\title{
ARTICLE OPEN \\ FcyRIII stimulation breaks the tolerance of human nasal epithelial cells to bacteria through cross-talk with TLR4
}

\author{
K. Golebski ${ }^{1,2}$, W. Hoepel ${ }^{1,3}$, D. van Egmond ${ }^{2}$, E. J. de Groot ${ }^{2}$, G. D. Amatngalim ${ }^{4,5}$, J. M. Beekman ${ }^{4,5}$, W. J. Fokkens ${ }^{2}$, \\ C. M. van Drunen ${ }^{2}$ and J. den Dunnen ${ }^{1,3}$
}

The nasal cavity displays immune tolerance to commensal bacteria under homeostatic conditions, which is rapidly converted to a pro-inflammatory response upon infection. Yet, the factors that control this conversion are still largely unknown. Here, we provide evidence that Fc gamma receptor III (FcyRIII) stimulation breaks immune tolerance to bacteria in the human nasal cavity through activation of nasal epithelial cells, which are the first line of defense against invading microbes. While under steady-state conditions human nasal epithelial cells were completely non-responsive to Gram-negative bacteria P. aeruginosa or TLR4 ligand LPS, IgG opsonization of bacteria, as occurs upon infection, strongly induced production of pro-inflammatory agents such as IL-6 and IL-8. This breaking of tolerance to bacteria was completely dependent on FcyRIIl, which amplified cytokine gene transcription through cross-talk with TLR4. In addition, we identified that epithelial cells from patients suffering from chronic rhinosinusitis with nasal polyps do not display LPS tolerance, thereby providing an explanation for the disturbed host defense responses of these patients. Taken together, these data are the first to identify FcyR expression on nasal epithelial cells, as well as to identify its important role in controlling the balance between tolerance and inflammation in the nasal cavity.

Mucosal Immunology (2019) 12:425-433; https://doi.org/10.1038/s41385-018-0129-x

\section{INTRODUCTION}

The nasal cavity is constantly exposed to many different bacterial species, between which the immune system should discriminate and induce tolerance to commensals, while inducing protective inflammatory responses against invading pathogens. ${ }^{1}$ Important for detection of microorganisms by immune cells are pathogensensing receptors known as pattern-recognition receptors (PRRs), which recognize conserved microbial structures such as LPS expressed by Gram-negative bacteria. ${ }^{1}$ However, since these conserved microbial structures are expressed by nearly all microorganisms, recognition through PRRs alone falls short to explain how the nasal immune system is able to distinguish between commensal and invading bacteria. Although additional factors must be involved in controlling the balance between tolerance and inflammation in the nasal cavity, the underlying mechanisms are still incompletely characterized.

Epithelial cells are the first line of defense against invading pathogens in the nasal cavity. ${ }^{2}$ Nasal epithelium expresses a variety of PRRs such as Toll-like receptors (TLRs), through which they can detect a variety of different pathogens, including viruses and bacteria. ${ }^{3}$ However, remarkably, nasal epithelial cells particularly produce pro-inflammatory cytokines and chemokines in response to viral stimuli, whereas the response to bacterial ligands is restricted. ${ }^{3}$ While this restricted response provides immune tolerance to commensal bacteria and is therefore beneficial under steady-state conditions, immune tolerance should be converted to an inflammatory response upon bacterial infection. Since epithelial cells express bacteria-sensing PRRs, a potential explanation is that these cells require a 'second signal', in addition to the continuous exposure to bacterial antigens, to switch from a tolerogenic to an inflammatory phenotype. However, it is still unclear how nasal epithelial cells convert from immune tolerant to pro-inflammatory cells.

In addition to acute inflammation that is induced in response to invading pathogens, chronic inflammation in the nasal cavity is observed in patients suffering from chronic rhinosinusitis with nasal polyps (CRSwNP). CRSwNP is a chronic inflammatory disease that affects up to $4 \%$ of the adult population that is characterized by mucosal inflammation of the nasal and paranasal sinuses and presence of nasal polyps, which are outgrowths of inflammatory tissue that have grown into the middle meatus. ${ }^{4}$ While the pathogenesis of CRSwNP is still poorly understood, CRSwNP is known to be associated with epithelial dysfunction that disturbs host-microbe interactions. ${ }^{5}$ However, the mechanisms responsible for these aberrant host defense responses by nasal epithelial cells are still largely unclear.

IgG is the most prevalent immunoglobulin in blood and tissue fluids. ${ }^{6,7}$ Under homeostatic conditions, the mucus layer of the nasal cavity contains relatively little lgG, while in contrast it contains high levels of secretory $\lg \mathrm{A}$, which is actively transported

\footnotetext{
${ }^{1}$ Department of Experimental Immunology, Amsterdam UMC, University of Amsterdam (UvA), Meibergdreef 9, Amsterdam, Netherlands; ${ }^{2}$ Department of Otorhinolaryngology, Amsterdam UMC, UvA, Meibergdreef 9, Amsterdam, Netherlands; ${ }^{3}$ Amsterdam Rheumatology \& Immunology Center (ARC), Academic Medical Center, Amsterdam, Netherlands;

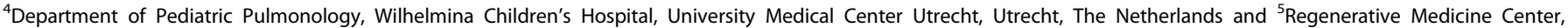
University Medical Center, Utrecht, The Netherlands

Correspondence: J den Dunnen (j.dendunnen@amc.nl)

These authors contributed equally: K. Golebski, W. Hoepel

These authors jointly supervised: C.M. van Drunen, J. den Dunnen
}

Received: 20 March 2018 Revised: 13 December 2018 Accepted: 21 December 2018

Published online: 21 January 2019 

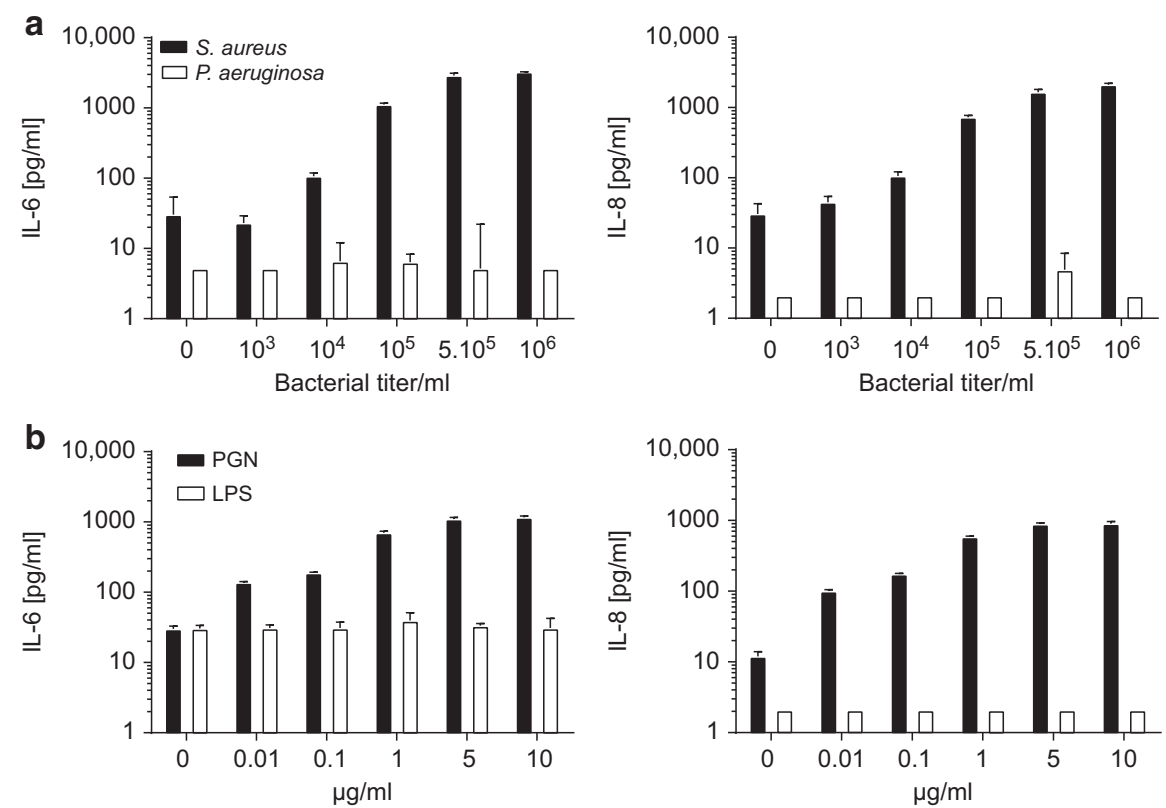

C

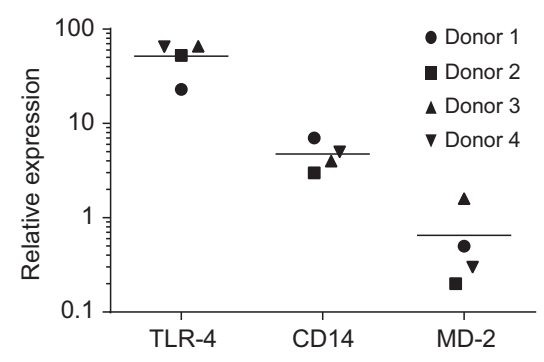

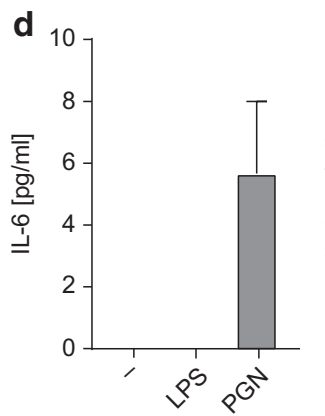

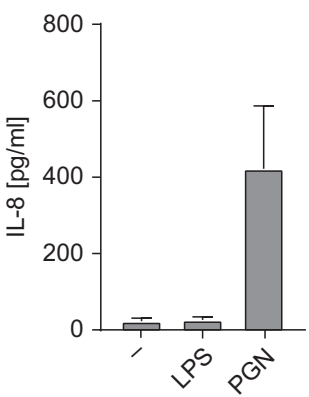

Fig. 1 Human nasal epithelial cells are unresponsive to $P$. aeruginosa and LPS. a Nasal epithelial cells were stimulated for $24 \mathrm{~h}$ with different titers of $P$. aeruginosa or $S$. aureus, after which IL-6 or IL-8 production was measured. b Nasal epithelium was exposed for $24 \mathrm{~h}$ to LPS or PGN, after which IL-6 and IL-8 production levels were measured. c mRNA expression of TLR4, CD14, and LY96 (encoding the MD-2 protein) genes were measured. Total RNA was isolated from nasal epithelial cells of four individuals. Relative gene expression levels were corrected for the expression of housekeeping gene GAPDH. d Human bronchial epithelial cells were exposed to LPS or PGN for $24 \mathrm{~h}$, after which IL-6 and IL-8 production levels were measured. $\mathbf{a}, \mathbf{b}$ and $\mathbf{d}$ are representative examples of four experiments using different donors, showing average values of triplicate measurement $+\mathrm{SD}$

from the lamina propria across the epithelium. ${ }^{8}$ As a result, under steady-state conditions (commensal) bacteria are predominantly opsonized by IgA. However, during conditions such as nasal inflammation, the levels of lgG in the nasal cavity dramatically increase through passive diffusion through bleeding and/or inflammatory exudate. ${ }^{8,9}$ Due to the high levels of IgG directed against common bacterial antigens under inflammatory conditions bacteria will therefore also become opsonized by $\operatorname{lgG} .^{10}$

Here, we provide evidence that IgG opsonization of Gramnegative bacteria, as occurs during infection, delivers a second signal to human nasal epithelial cells that breaks immune tolerance of these cells. We demonstrate that this breaking of tolerance to Gram-negative bacteria is dependent on cross-talk between Fc gamma receptor III (FcyRIII, also known as CD16) and TLR4. Interestingly, we show that epithelial cells from nasal polyps of CRSwNP patients do not show immune tolerance to TLR4 ligands and Gram-negative bacteria, and consequently also show less FcyRIII-TLR4 cross-talk, which provides a potential explanation for the disturbed host-microbe responses in CRSwNP patients. These data are the first to identify that nasal epithelial cells express FcyRs and indicate that FcyRIII has an important role in controlling the balance between tolerance and inflammation in the nasal cavity.

\section{RESULTS}

Human nasal epithelial cells are unresponsive to $P$. aeruginosa and LPS

Bacterial species that reside in or invade the nasal cavity may either induce immune tolerance or pro-inflammatory responses. Here, we set out to determine the immunological response of human nasal epithelial cells to pathogenic Gram-negative bacterium $P$. aeruginosa, which is capable of causing a broad range of infections of the respiratory airways and is the leading cause of morbidity and mortality in patients with cystic fibrosis. ${ }^{11}$ Responses were compared to stimulation with Gram-positive bacterium $S$. aureus. For this, we exposed human nasal epithelial cells to increasing titers of bacterial cells and measured cytokine and chemokine production. Stimulation with $S$. aureus strongly induced the production of pro-inflammatory cytokines IL- 6 and IL8 (Fig. 1a). However, in stark contrast, exposure of epithelial cells to Gram-negative bacterium $P$. aeruginosa did not induce any detectable levels of IL- 6 or IL-8, even upon stimulation with the highest bacterial cell titer (Fig. 1a). These data demonstrate that nasal epithelial cells induce distinct immunological responses in response to different bacterial species.

Next, we set out to investigate these observations in greater detail. Gram-negative bacteria such as $P$. aeruginosa are mostly 
sensed through recognition of bacterial cell wall component LPS by TLR4, while Gram-positive bacteria express PGN that is recognized by other receptors such as TLR2 and NLRs. Notably, whereas stimulation with PGN strongly upregulated IL-6 and IL-8 production by nasal epithelial cells (Fig. 1b), even at very low concentrations $(10 \mathrm{ng} / \mathrm{ml})$, stimulation with LPS did not induce any detectable production/release of IL-6 and IL-8 (Fig. 1b), even after exposure to extremely high LPS concentrations (up to $10 \mu \mathrm{g} / \mathrm{ml}$ ), which is in line with our previous observations. ${ }^{1,12}$ This lack of response to LPS was not caused by lack of expression of TLR4 or associated genes, since nasal epithelial cells of all donors showed detectable levels of TLR4, CD14, LY96 (encoding the MD-2 protein), and CD180 (encoding the RP105 protein), while LY86 (encoding the MD-1 protein) expression was very low (Fig. 1c and Suppl. Figure 1). These data demonstrate that human nasal epithelial cells are unresponsive to LPS.

Since local conditions such as microbial load can vary depending on the tissue involved, immune responses could be orchestrated in a tissue-specific manner as well. To determine whether LPS tolerance is specific for nasal epithelium, or whether this is a more common phenomenon, we assessed the response of primary lung epithelial cells. Similar to the nasal epithelium, lung epithelial cells elicited little to no IL- 6 and IL-8 production in response to LPS (Fig. 1d). Lung epithelial cells did respond to $(1 \mu \mathrm{g} / \mathrm{ml})$ PGN, similar to nasal epithelium (Fig. 1d).

Combined, these data indicate that airway epithelium is unresponsive to $P$. aeruginosa and LPS.

\section{IgG opsonization of $P$. aeruginosa breaks tolerance of nasal epithelium}

During infection of the nasal cavity, invading bacteria are efficiently opsonized by high levels of cross-reactive lgG. ${ }^{10}$ Here, we set out to determine whether IgG opsonization of bacteria affects the immunological response of nasal epithelium. First, we verified that bacteria were indeed opsonized by human serum IgG using a binding $\operatorname{ELISA}^{10}$ (Fig. 2a). Subsequently, we assessed the effect of lgG opsonization of bacteria on cytokine production by nasal epithelial cells. Strikingly, lgG opsonization of $P$. aeruginosa strongly upregulated IL-6 and IL-8 production compared to non-opsonized conditions (representative example Fig. 2b; multiple donors Fig. $2 \mathrm{c}$ ). Similar responses were observed upon $\mathrm{lgG}$ opsonization of $\mathrm{H}$. influenzae, another Gram-negative bacterium (Suppl. Figure 2A). In contrast, IgG opsonization had no effect on the induction of cytokines in response to $S$. aureus (representative example Suppl. Figure 2B; multiple donors Suppl. Figure 2C).

These data indicate that IgG opsonization of Gram-negative bacteria, as occurs upon infection, breaks immune tolerance of nasal epithelium to these pathogens.

\section{Stimulation with human serum IgG breaks tolerance of nasal epithelium to LPS}

To assess whether IgG directly induces inflammatory responses by nasal epithelium, we stimulated epithelial cells with human serum $\mathrm{lgG}$. However, individual stimulation with IgG did not induce any cytokine production beyond unstimulated conditions (Fig. 3a). Since TLR4 is one of the main receptors for Gramnegative bacteria, we next determined whether the combination of IgG and TLR4 ligand LPS induces pro-inflammatory responses. Importantly, simultaneous stimulation of nasal epithelial cells with IgG and LPS strongly induced the production of pro-inflammatory cytokines IL- 6 and IL-8 (representative example Fig. 3a; multiple donors Fig. 3b), indicating that costimulation with human IgG breaks the tolerance of nasal epithelium to LPS.

Cytokine production can be regulated at different levels. To study whether the observed amplification of pro-inflammatory cytokine/chemokine production by nasal epithelial cells is reflected at the transcriptional level, we analyzed IL- 6 and IL-8 gene expression profile in nasal epithelium in a $24 \mathrm{~h}$ time course after stimulation with LPS and/or IgG. While individual stimulation with IgG or LPS did not induce any IL6 and IL8 gene transcription, simultaneous stimulation with LPS and IgG did induce IL6 and IL8 gene transcription (Fig. 3c). Similarly, co-stimulation with IgG enhanced mRNA expression of other genes such as TNF and CCL20 (Suppl. Figure 3).

In addition to the submerged epithelial cell cultures, we also tested the response of epithelial cells in an air-liquid interface culture, which we stimulated with LPS and/or IgG on either the apical or the basolateral side. In general, cytokine production by these cultures was very low. Yet, while we could not detect cytokine production upon stimulation of the basolateral side, we did observe enhanced IL-6 production upon co-stimulation of LPS with IgG on the apical side (Suppl. Figure 4). These findings suggest that apical IgG exposure breaks LPS tolerance, while basolateral exposure does not.

Besides nasal epithelial cells, we also assessed the effect of lgG co-stimulation of (submerged) lung epithelial cells. Similar to nasal epithelium, co-stimulation with IgG strongly increased cytokine production by lung epithelial cells (Fig. 3d).

Combined, these data indicate that exposure to IgG to the apical side breaks the tolerance of airway epithelium to LPS by increasing cytokine gene transcription.

Breaking of LPS tolerance by lgG is mediated by FcyRIII The main receptors for the recognition of IgG are the family of FcyRs. However, with the exception of the neonatal Fc receptor (FcRn), ${ }^{13}$ thus far FcyRs have not been described to be expressed by human nasal epithelium. To determine whether nasal epithelial cells express conventional FcyRs, we assessed gene expression levels of FCGR1 (FcyRl), FCGR2 (FcyRII), and FCGR3 (FcyRIII). Interestingly, nasal epithelial cells expressed FCGR3 (FcyRIII), while expression of FCGR1 (FcyRl) and FCGR2 FcyRll was very low (Fig. 4a). Subsequently, FcyRIII expression was confirmed at protein level by Western blot (Fig. 4b).

Next, we set out to determine whether any of the conventional FcyRs are responsible for the enhanced IL- 6 and IL- 8 production by using specific blocking antibodies. Importantly, blocking of FcyRIII completely inhibited IgG-induced amplification of IL- 6 and IL-8 production, while blocking of $\mathrm{Fc} \gamma \mathrm{RI}$ and $\mathrm{Fc}$ RII had no effect (representative example Fig. 4c; multiple donors Fig. 4d). To verify that the inhibition of IgG-induced cytokine production by antiFcyRIII antibodies is not caused by the potential triggering of inhibitory FcyRs on epithelial cells, we assessed whether exposure to the anti-FcyRIII antibody affects cytokine production in general by nasal epithelial cells (in this case upon stimulation with PGN). As shown in Suppl. Figure 5, anti-FcyRIII antibodies did not suppress PGN-induced cytokine production, indicating that the anti-FcyRIII antibody itself does not induce inhibitory signaling by nasal epithelial cells.

FcyRs can signal via Syk-dependent and/or Syk-independent pathways. ${ }^{14,15}$ Surprisingly, inhibition of Syk (using therapeutic inhibitor R406 ${ }^{16,17}$ ) did not counteract FcyRlll-induced cytokine production (Suppl. Figure 6A). To test this in greater detail, we also assessed whether Syk activation by other means (in this case curdlan-induced Dectin-1 stimulation) has a similar effect as FcyRIII on breaking LPS tolerance. However, in line with the lack of effect of Syk inhibition, co-stimulation of Dectin-1 and TLR4 did not further amplify cytokine production (Suppl. Figure 6B). These data indicate that FcyRIII-induced abrogation of LPS tolerance is independent of signaling through the kinase Syk.

Taken together, these data not only identified that nasal epithelial cells express FcyRIII, but also identified the functional role of FcyRIII on these cells, i.e., to break tolerance to LPS in response to co-stimulation with IgG during infection or trauma. 


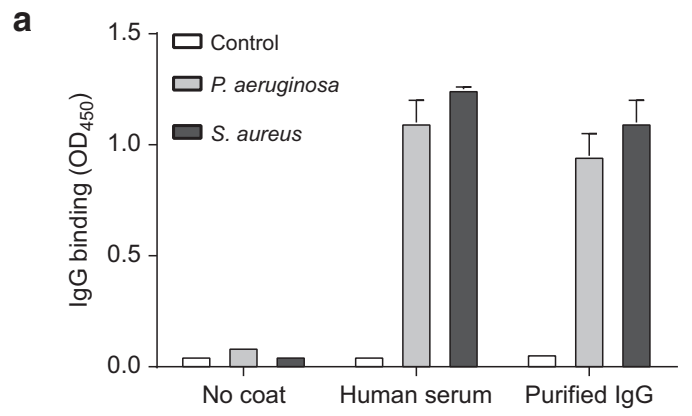

b
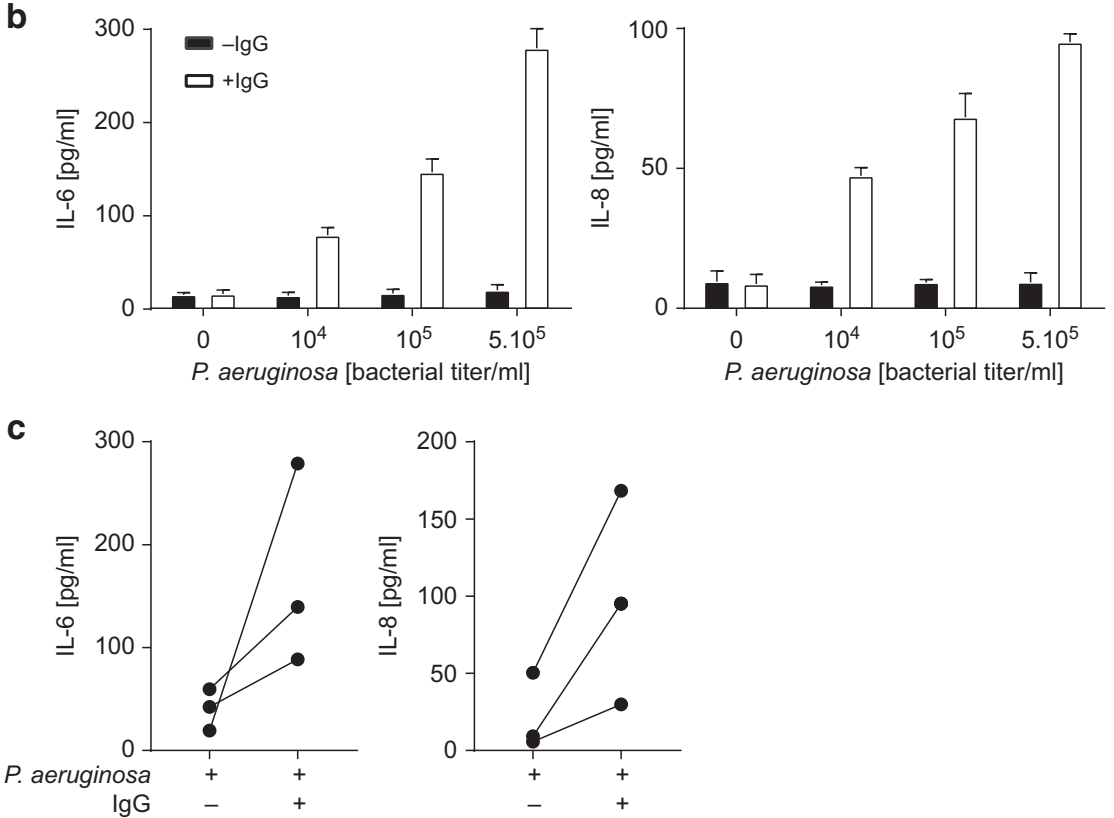

Fig. 2 IgG opsonization of bacteria breaks tolerance of nasal epithelium to $P$. aeruginosa. a 96-well plate was coated with bacteria and incubated with a control antibody, human serum, or purified IgG. Data shown are average values of triplicate measurement from one representative experiment out of three $+\mathrm{SD}$. b Nasal epithelium was stimulated for $24 \mathrm{~h}$ with different titers of $P$. aeruginosa that were opsonized or not with human serum IgG, after which IL-6 and IL-8 production was measured in supernatants. Representative example of three experiments using different donors, showing average values of triplicate measurement from one representative donor + SD. c IL-6 and IL-8 production of nasal epithelium after $24 \mathrm{~h}$ stimulation with $5.10^{5} \mathrm{CFU} / \mathrm{ml} P$. aeruginosa opsonized or not with human serum IgG. Each pair of dots represents one donor

Epithelial cells from nasal polyps of CRSwNP patients do not show LPS tolerance

Thus far, we had investigated the response of nasal epithelium of healthy individuals. Next, we investigated TLR4-FcyRIII costimulation of epithelial cells from nasal polyps of CRSwNP patients. Although expression levels varied, nasal polyp epithelial cells from all donors expressed FcyRIII (Fig. 5a). Upon side-byside comparison, nasal polyp epithelial cells showed a somewhat higher expression of FcyRIII than epithelial cells from healthy individuals, while TLR4 expression was comparable (Suppl. Figure 7).

In stark contrast to healthy donors, stimulation with LPS alone (i.e., in absence of co-stimulation with $\mathrm{lgG}$ ) strongly induced IL-6 and IL-8 production by epithelial cells from nasal polyps (representative example Fig. 5b; multiple donors Fig. 5c), indicating that epithelial cells from CRSwNP patients display a lack of immune tolerance to LPS. Co-stimulation of LPS with IgG significantly upregulated IL- 6 and IL- 8 production by epithelial cells from nasal polyps, but not as pronounced as in epithelial cells from healthy tissue.

Taken together, these data indicate that, in contrast to healthy nasal epithelium, nasal polyp epithelial cells are not unresponsive to LPS, and that FcyRIII co-stimulation of nasal epithelial cells from polyps has relatively little additional effect on the induction of inflammation.

\section{DISCUSSION}

In various tissues, recognition of microbial components through PRRs directly induces pro-inflammatory responses. ${ }^{18}$ However, in tissues characterized by the presence of commensal microorganisms such as the nasal cavity, steady-state PRR activation coincides with immune tolerance, indicating that the host immune system requires additional mechanisms to discriminate between commensal and invading microorganisms. Here, we provide evidence that in the nasal cavity the presence of IgG immune complexes, as a result of IgG opsonization of bacteria, acts as a second signal that breaks nasal immune tolerance. While individual TLR4 stimulation (as occurs under homeostatic conditions) does not elicit cytokine production by nasal epithelial cells, concomitant stimulation of FcyRIII (as occurs during infection) strongly amplifies cytokine and chemokine gene transcription (for model see Fig. 6). In addition, we identified that epithelial cells from nasal polyps of CRSwNP patients do not display tolerance to TLR4 ligands, providing an explanation for the inflammatory phenotype of these cells to commensal bacteria. 

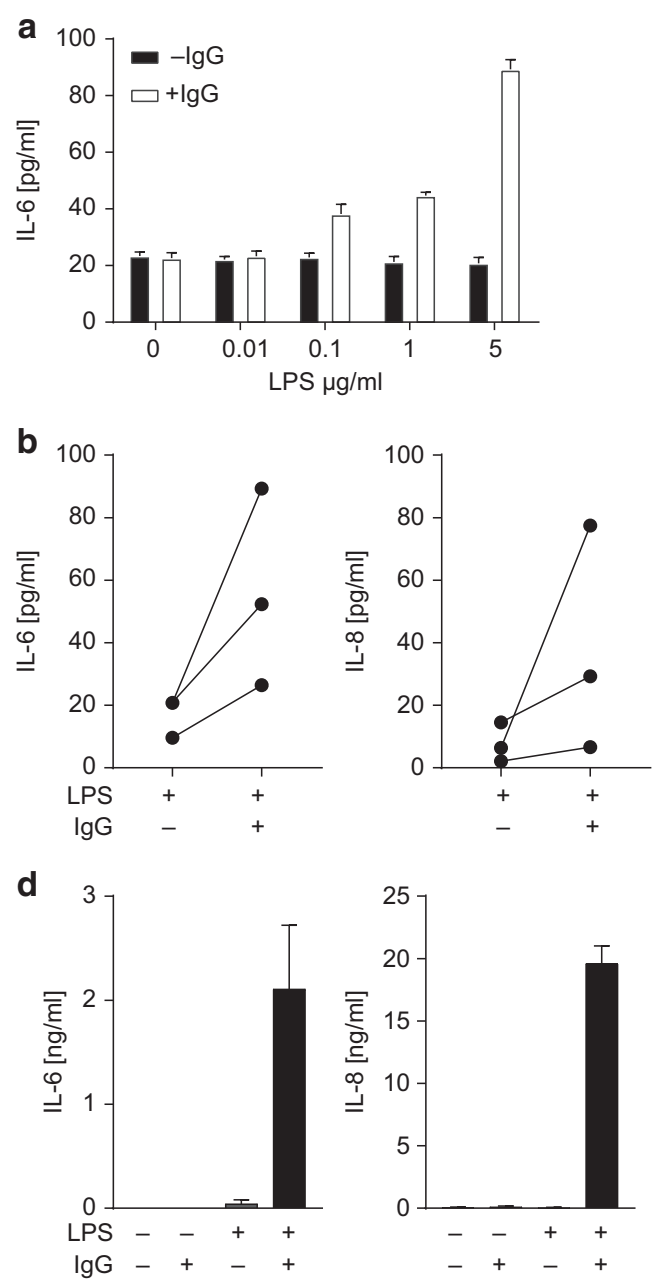
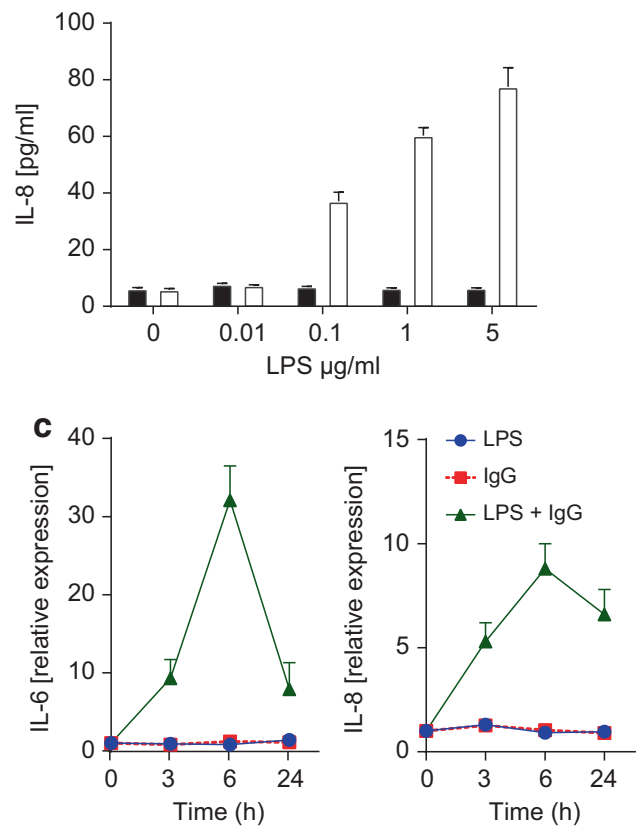

Fig. 3 Co-stimulation with human serum IgG breaks the tolerance of nasal epithelium to LPS. a Nasal epithelium was exposed for $24 \mathrm{~h}$ to increasing doses of LPS and co-stimulated with IgG or not. IL-6 and IL-8 production levels were measured in supernatants. $\mathbf{b}$ IL- 6 and IL-8 production of nasal epithelium after $24 \mathrm{~h}$ stimulation with $5 \mu \mathrm{g} / \mathrm{ml}$ LPS with or without lgG. Each pair of dots represents one donor. c Gene expression levels of $I L 6$ and $I L 8$ were quantified in cells stimulated with $5 \mu \mathrm{g} / \mathrm{ml}$ of LPS with or without lgG in a time course over $24 \mathrm{~h}$. Relative expression levels were corrected for the expression of housekeeping gene GAPDH and compared to non-stimulated control conditions $\mathbf{d}$ IL- 6 and IL-8 production of human bronchial epithelial cells after $24 \mathrm{~h}$ stimulation with $5 \mu \mathrm{g} / \mathrm{ml}$ LPS with or without lgG. a and c are representative examples of three experiments using different donors, showing average values of triplicate measurement from one representative donor + SD

It is becoming increasingly clear that airway epithelial cells do not simply function as a passive physical barrier for microorganisms, but also play an important role in orchestrating immune responses to invading pathogens. ${ }^{2}$ To sense these pathogens, airway epithelial cells are equipped with a variety of PRRs. ${ }^{3}$ Epithelial cells in the nasal cavity induce restricted responses to PRR activation, in order to provide immune tolerance to the relatively high number of commensal bacteria. This nonresponsiveness of nasal epithelium to bacteria-sensing PRRs such as TLR4 does not seem to result from decreased receptor expression, since TLR4, CD14, and MD-2 are all expressed by nasal epithelial cells, suggesting that TLR4 activation is inhibited in a different manner, e.g. by inhibition of downstream signaling. Here, we identified that the restricted TLR4 activation in nasal epithelial cells can be restored by concomitant stimulation of FcyRIII, which thereby initiates the transition from immune tolerance to protective immunity.

To our knowledge, we are the first to identify expression of activating FcyRs on human nasal epithelial cells. FcyRs are considered to be mainly expressed by myeloid immune cells, such as dendritic cells, macrophages, and neutrophils. ${ }^{19}$ More specifically, FcyRIII is considered to be mainly expressed by NK cells and cells of the monocyte/macrophage lineage. ${ }^{20}$ Interestingly, it has recently been identified that nasal epithelial cells express the human neonatal FcR (FcRn). ${ }^{13}$ While FcRn is not a classical immune activating or inhibitory $F c \gamma R$, but mainly mediates antibody recycling and transcytosis, ${ }^{21}$ this already hinted towards the involvement of IgG antibodies in the immunological function of epithelial cells. Here, we identified that the role of lgG in the nasal cavity is even substantially more pronounced than previously considered, by functional expression of FcyRIII.

Importantly, FcyRIII is a low-affinity receptor for $\operatorname{lgG}^{20}$ which is most likely crucial to exert its function of balancing immune tolerance and inflammation in the nasal cavity. Under steady-state conditions, nasal epithelial cells are not only exposed to LPS from commensal bacteria, but also to high concentrations of IgG at the basolateral side and low(er) lgG concentrations at the apical side, which is mainly present as monomeric lgG. However, because of the low affinity of FcyRIII for monomeric IgG this will not lead to FcyRIII activation, but instead may even suppress inflammatory responses through inhibitory ITAM signaling. ${ }^{22}$ In contrast, infection of the nasal cavity triggers the release of lgG directed against bacterial antigens, leading to the formation of immune complexes that bind to and activate low-affinity receptor FcyRIII, 

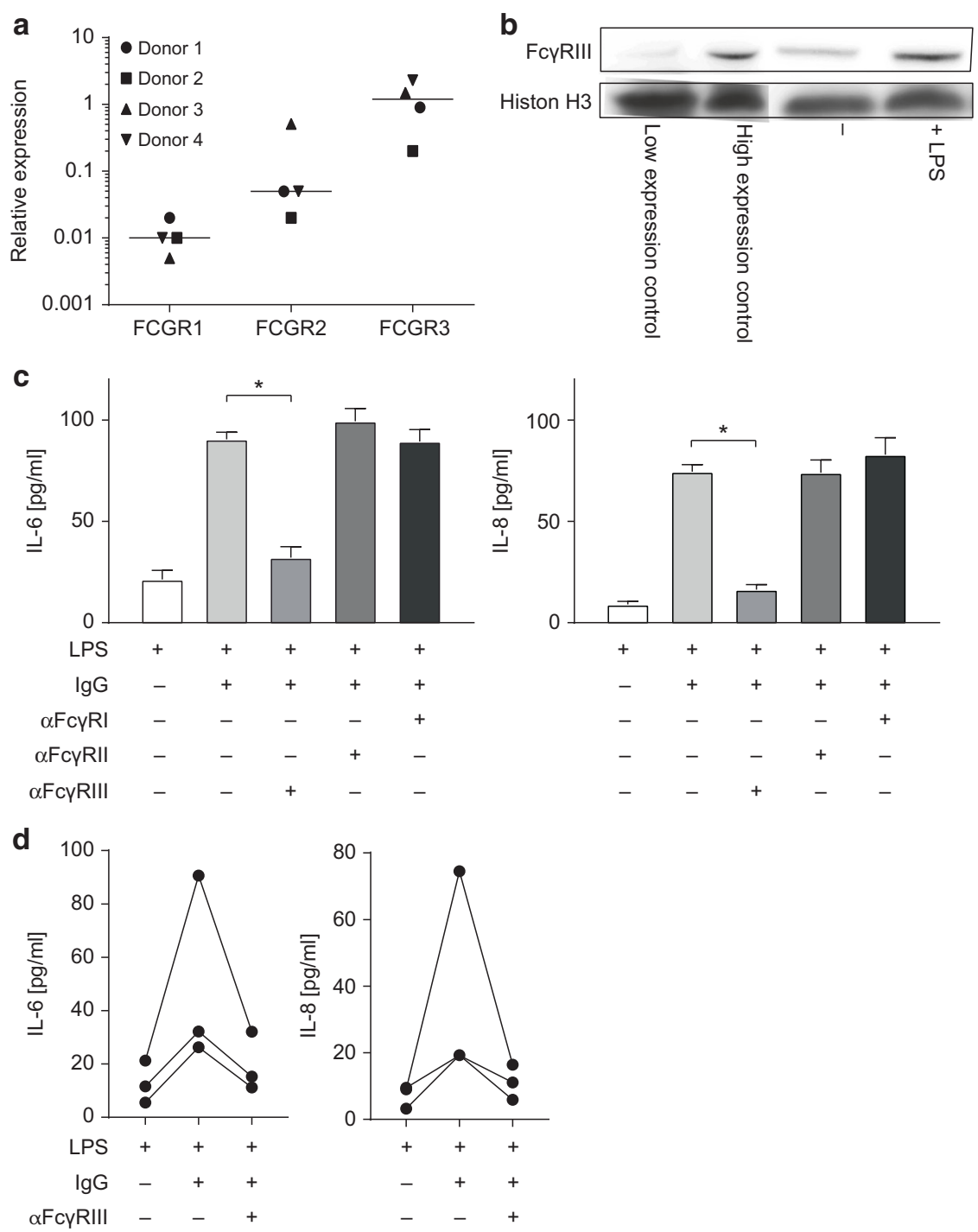

Fig. 4 Breaking of LPS tolerance by lgG is mediated by FcyRIII. a Expression levels of FCGR1 (CD64), FCGR2 (CD32), and FCGR3 (CD16) were measured by isolating total RNA from nasal epithelial cells of four individuals. Relative gene expression levels were corrected for the expression of housekeeping gene GAPDH. b Protein expression of FcyRIII was measured by western blot. As positive and negative controls, lysates were used from cells with known high (human macrophages) or low (human dermal fibroblast) FcyRIII expression. c Nasal epithelium was pre-incubated for 30 min with or without a blocking antibody against FcyRl, FcyRII, or FcyRIII and then stimulated with LPS with or without IgG. IL-6 and IL-8 levels were measured in supernatants. Representative examples of three experiments using different donors, showing average values of triplicate measurement from one representative donor $+\mathrm{SD} .{ }^{*} p<0.05$. d IL-6 and IL-8 production of nasal epithelium pre-incubated for 30 min with or without a blocking antibody against Fc $\gamma$ RIII and then stimulated with LPS with or without IgG. Each triplicate of dots represents one donor

most likely at the apical side. As such, it is not the presence of lgG itself, but the formation of lgG immune complexes that provides the environmental cue for nasal epithelium to break immunological tolerance for bacteria.

Our data indicate a more profound role for antibodies of the lgG isotype in mucosal immunology than previously considered. In general, the main antibody isotype at mucosal sites is considered to be $\lg A$, while $\lg G$ is the main isotype in blood and tissue fluids. $^{20,23,24}$ However, this 'division of labor' by the different isotypes is unlikely to be black and white, considering the high concentrations of IgA in serum on one hand, and the levels of IgG in mucosal tissues on the other hand. Indeed, it has recently been shown that $\lg \mathrm{A}$ in serum is important for shaping anti-bacterial responses in tissues such as blood, skin, and liver. ${ }^{25}$ Alternatively, here our data indicate that IgG plays an important role in providing protective host defense against bacteria in mucosal tissue. For future research, it would be very interesting to investigate whether this pro-inflammatory function of IgG is only functional in epithelial cells of the airways, or if it also occurs at other epithelial sites that are characterized by the presence of commensal bacteria, such as the intestine.

Remarkably, while nasal epithelial cells are non-responsive to TLR4 ligand LPS, these cells do (moderately) respond to other bacteria-derived ligands such as PGN, which is recognized by TLR2 and NOD-like receptors. The reason for this difference in responsivity, both from a functional and mechanistic point of view, is still largely unclear. Since LPS is only expressed by Gramnegative bacteria and PGN is only expressed on the surface of Gram-positive bacteria, these data suggest that nasal epithelium is more tolerogenic for Gram-negative than for Gram-positive bacteria. Indeed, previous findings advocate a strong role for Gram-positive bacteria such as $S$. aureus in chronic nasal inflammation. ${ }^{26}$ However, this distinction between Gram-positive and negative bacteria is most likely not black and white, since 
a

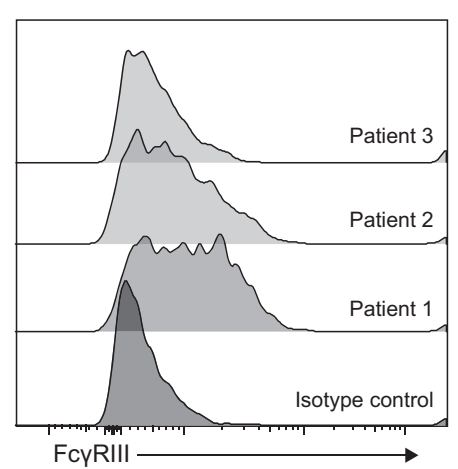

b

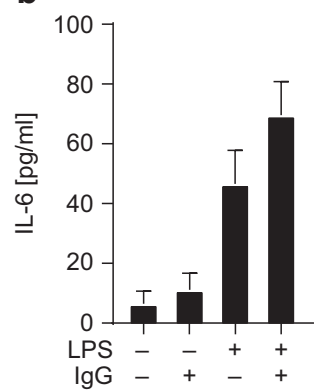

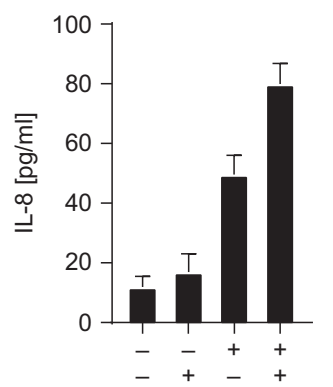
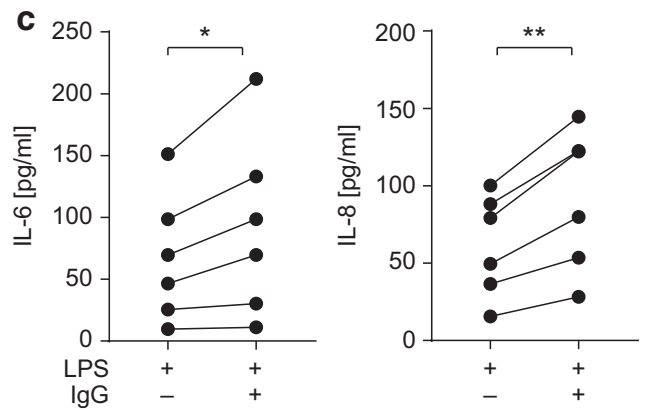

Fig. 5 Epithelial cells from nasal polyps do not show LPS tolerance, and less FcyRIII-TLR4 cross-talk. a Expression of FcyRIII on epithelial cells of nasal polyps of CRSwNP patients measured by flow cytometry. $\mathbf{b}$ Nasal polyps were exposed for $24 \mathrm{~h}$ to LPS and co-stimulated or not with lgG. IL-6 and IL-8 production levels were measured in supernatants. Representative example of six experiments using different donors, showing average values of triplicate measurement from one representative donor + SD. c IL-6 and IL-8 production of nasal polyps after $24 \mathrm{~h}$ exposure to LPS with or without IgG. Each pair of dots represents one donor. ${ }^{*} p<0.05$ or ${ }^{* *} p<0.01$

pathogens are mostly recognized by multiple PRRs simultaneously. Therefore, upon bacterial recognition the relative contribution of a PRR (TLR4, TLR2, NOD-like receptors, etc.) will ultimately determine whether the response of nasal epithelial cells will be more tolerogenic or inflammatory. Indeed, our data indicate (small) variations in responsivity to Gram-negative bacteria, with no response whatsoever to $P$. aeruginosa (which may mainly depend on TLR4), but a little bit of cytokine production in response to $H$. influenzae (which may also partially depend on other PRRs). Consequently, also the relative effect of FcyRIII co-activation of nasal epithelial cells will differ depending on the pathogen involved, with strong FcyRIII-induced inflammatory changes in response to bacteria that are mainly sensed through TLR4, but less (additional) inflammation by FcyRIII in response to bacteria that are mainly sensed by other PRRs.

Importantly, we identified that epithelial cells from nasal polyps of CRSwNP patients, in contrast to epithelial cells from healthy individuals, strongly respond to TLR4 stimulation. Although the etiology of CRS is still unknown, it has previously been hypothesized that the pro-inflammatory state of CRS relates to a lack of tolerance to commensal organisms. ${ }^{27}$ Our data strongly support this hypothesis by demonstrating that epithelial cells from nasal polys do not display tolerance to TLR4 stimulation, and therefore most likely continuously induce pro-inflammatory responses upon exposure to commensal Gram-negative bacteria. In addition, the lack of efficient FcyRIII-TLR4 cross-talk in nasal polyp epithelial cells impedes their capacity to discriminate between homeostatic conditions and bacterial infection. Although still speculative, these data may indicate that the pathway induced by FcyRIII, which in healthy epithelium is essential for functional TLR4 activation, is constitutively activated in polyp epithelial cells, even in absence of FcyRIII stimulation. The nature of this pathway is still unknown, since it is not dependent on signaling through Syk, the key kinase of canonical FcyR signaling, ${ }^{14}$ but on Syk independent FcR signaling, reminiscent of the recently identified non-canonical pathway of the FcyR family. ${ }^{15}$ Identification of this pathway by future studies may have important clinical implications. For example, therapies that target this mechanism in CRS patients may prevent LPS-driven inflammation by nasal polyps under homeostatic conditions, thereby restoring the tolerance of nasal epithelium to commensal bacteria. In addition, targeting of this pathway may limit hyper-responsiveness (e.g. as observed during sepsis) under infectious conditions.

Taken together, these data indicate that human nasal epithelial cells can discriminate between commensal vs. invading bacteria by sensing of IgG immune complexes through FcyRlll, which breaks immune tolerance of these cells to TLR4 ligands. From a therapeutic point of view, targeting of this FcyRlll-induced pathway may be a valuable approach to attenuate chronic inflammation in patients suffering from CRSwNP.

\section{METHODS}

Patient characteristics

Inferior turbinate tissue was obtained from patients who underwent corrective surgery for turbinate hypertrophy with or without septoplasty. These patients had no history of allergic disease and their non-atopic status was confirmed with a negative Skin Prick Test for 18 of the most common aeroallergens. Nasal polyps were obtained from CRSwNP patients undergoing Endoscopic Sinus Surgery (ESS). None of the subjects had a current respiratory tract infection, none of them suffered from asthma and none of them was treated with nasal corticosteroids or other nasal medication in the 4 weeks prior to inclusion. In addition, patients that smoked were excluded. Under Dutch law, tissue removed during mandatory surgery (so not specifically removed for a research purposes) can be used for research when the origin cannot be traced back to the patient. Despite the fact that there is no legal obligation, patients were informed of the intention to use their waste material and the patients consented. 

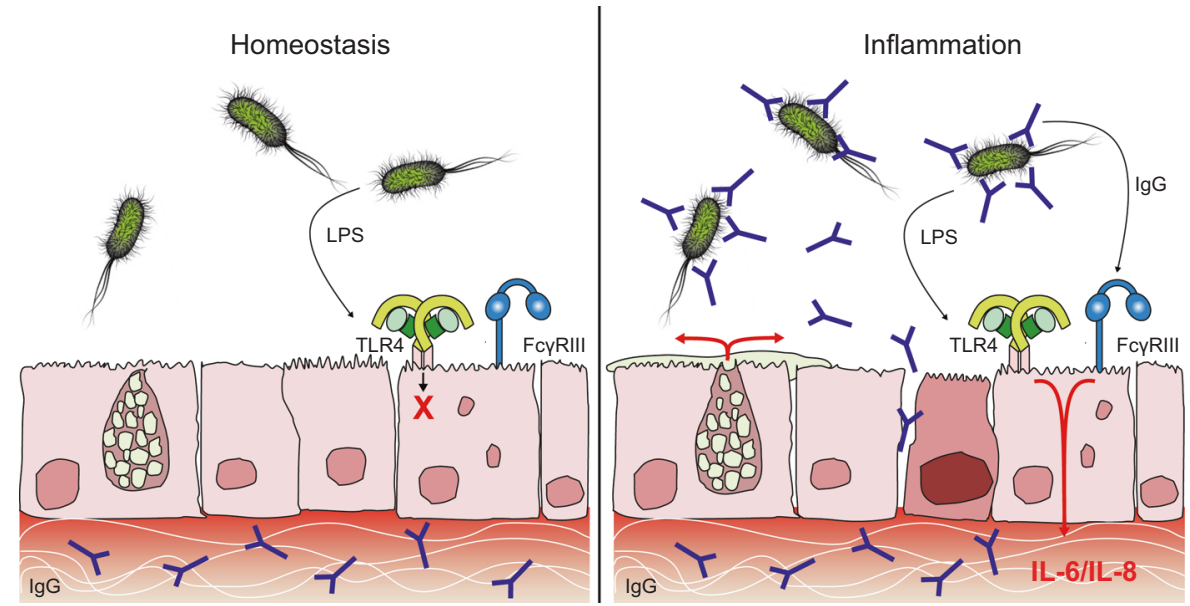

Fig. 6 Model of FcyRIII-TLR4 cross-talk in human nasal epithelium. Under homeostatic conditions, human nasal epithelial cells are nonresponsive to TLR4 activation by Gram-negative bacteria, thereby providing immune tolerance to commensals. During infection, high levels of IgG enters the nasal cavity, leading to IgG opsonization of bacteria. These opsonized bacteria simultaneously activate TLR4 and FcyRIII at the apical surface of the airway epithelial cells. Combined stimulation of Fc $\gamma$ RIII and TLR4 strongly promotes the production of pro-inflammatory agents such as IL- 6 and IL-8, thereby breaking immune tolerance to bacteria

\section{Cell and bacteria cultures}

Primary nasal epithelial cells were obtained by digesting nasal turbinates or nasal polyps with $0.5 \mathrm{mg} / \mathrm{ml}$ collagenase IV (Worthington Biochemical Corp., USA) for $1 \mathrm{~h}$ in Hanks' balanced salt solution (HBSS; Sigma-Aldrich,NL) with a subsequent incubation with anti-EpCAM MicroBeads (Miltenyi Biotec, DE) and a positive selection on a magnetic column. Retained cells were grown in a $75 \mathrm{ml}$ flasks in BEGM growth medium (Lonza Clonetics, NL). Culture medium was replaced every other day. Cells were grown in fully humidified air containing $5 \% \mathrm{CO}_{2}$ at 37 ${ }^{\circ} \mathrm{C}$. Primary lung epithelial cells (NHBE, Lonza) were cultured according to the manufacturer's protocol. The air-liquid interface culture system was set up as previously described by Callejas et al. $^{28}$

Sheep blood agarose plates were inoculated with $S$. aureus (RN4220), $P$. aeruginosa, or $H$. influenza overnight at $37^{\circ} \mathrm{C}$. The bacteria strains were a kind gift of Dr. S.A.J. Zaat (Medical Microbiology, Academic Medical Center in Amsterdam). Bacteria were then removed from plates and transferred to PBS. $\mathrm{OD}_{600}$ was measured to determine the bacteria cell count.

\section{Experimental setup}

Primary nasal epithelial cells, nasal polyps or primary lung epithelial cells were cultured to $80 \%$ confluence in 12 -well plates. Culture medium was replaced with serum-free RPMI 1640 medium containing $100 \mathrm{U} / \mathrm{ml}$ of penicillin and $100 \mu \mathrm{g} / \mathrm{ml}$ of streptomycin $24 \mathrm{~h}$ before stimulations. In the experiment with epithelium exposure to TLR agonists, cells were stimulated with $0.01,0.1,1.0$, 5.0, or $10.0 \mu \mathrm{g} / \mathrm{ml}$ of LPS or PGN (Sigma-Aldrich), in the presence or absence of $100 \mu \mathrm{g} / \mathrm{ml}$ of human serum IgG (Sigma-Aldrich) in a time course over $24 \mathrm{~h}$. Additionally, for the blocking experiments cells were pre-incubated for $20 \mathrm{~min}$ with $20 \mu \mathrm{g} / \mathrm{ml}$ of antibodies against: FcyRI (10.1; BD Biosciences; IgG1 k), FcyRII (IV.3; StemCell Technologies; IgG2b K), or FcyRIII (3G8; BD Biosciences; lgG1 K) and then stimulated with LPS or PGN and/or IgG for $24 \mathrm{~h}$. To block Syk with the inhibitor R406 (Selleckchem), cells were pre-incubated for $1 \mathrm{~h}$ with $1 \mu \mathrm{M}$ R406 and then stimulated with LPS and/or IgG for $24 \mathrm{~h}$. In the experiment with the Curdlan and LPS, cells were stimulated with $10 \mu \mathrm{g} / \mathrm{ml}$ Curdlan (Sigma-Aldrich, DE) and/or LPS for $24 \mathrm{~h}$. Cells were harvested with lysis buffer for RNA extraction and supernatants were collected for cytokine analysis. For the experiment with $S$. aureus, $P$. aeruginosa, or $\mathrm{H}$. influenza, bacteria were opsonized with $100 \mu \mathrm{L}$ of $5 \mathrm{mg} / \mathrm{ml}$ human serum IgG (SigmaAldrich, DE) for $1 \mathrm{~h}$ at room temperature and washed with RPMI medium. Epithelial cells were stimulated with opsonized or not $S$. aureus, $P$. aeruginosa, or $H$. influenza $\left(10^{3}\right.$ to $10^{6}$ cells $\left./ \mathrm{ml}\right)$ for $24 \mathrm{~h}$ and supernatants were collected for cytokines analysis.

RNA extraction and real-time quantitative PCR analysis Quantitative polymerase chain reaction (qPCR) was used to determine the differential expression of selected genes. Extracted mRNA (Nucleospin RNA II kit, Machery-Nagel, DE) was used for cDNA synthesis with the MBI Fermentas first strand cDNA kit (Thermo Scientific, NL). cDNA transcripts were quantified by realtime quantitative PCR (iCycler iQ MultiColor Real-Time PCR Detection System; Bio-Rad, FR) with specific primers and $\mathrm{IQ}^{\mathrm{TM}}$ SYBR Green Supermix (Bio-Rad, FR). The following Sybr Green primers were used for the PCR reactions: GAPDH: 5'-GAAGGTGAAGGTCGGAGTC-3' and 5'-GAAGATGGTGATGGGATTTC-3; IL-6: 5'-TGACAAACAAATTCGGTACATCCT-3' and 5'-AGTGCCTCTITGCTG CTITCAC-3'; IL-8: 5'-CCACACTGCGCCAACACAGAAATTATTG-3' and 5'-GCCCTCTTCAAAAACTTCTCC ACAACCC-3'; FCGR3 (CD16): 5'CGC AAG CTT TGG TGA CTG GTC CAC TC-3' and $5^{\prime}$-CGC TCT AGA TCA TGG GCT TाT CC CT-3'; FCGR2 (CD32): GCC CTC TCT GTG GAT CCC TAC TGC-3' and 5'-TCT TCT GGA GCT TCC GAC TGC A-3'; FCGR1 (CD64): 5'-CTT CTC CTT CTA TGT GGG CAG T-3' and 5'-GCT ACC TCG CAC CAG TAT GAT-3', TLR4: 5'-TAC AAA ATC CCC GAC AAC CTC-3' and 5'-AGC CAC CAG CTT CTG TAA ACT-3', CD14: 5'CGC TCC GAG ATG CAT GTG-3' and 5'-AAC GAC AGA TTG AGG GAG TTC AG-3'.

The following Taqman primers (Thermo Scientific, NL) were used for MD2 (Hs01026734_m1), MD1 (Hs01100589_m1), RP105 (Hs00194403_m1), TNF (Hs00174128_m1), CCL20 (Hs00355476_m1), and GAPDH (4310884E).

Expression levels of evaluated genes were calculated using the comparative $\Delta \Delta \mathrm{Ct}$ method. Each value was corrected for the expression of the housekeeping gene GAPDH and compared to the control condition. Data were analyzed in the Bio-Rad CFX Manager program (Bio-Rad, FR).

Flow cytometry

FcyRIII expression on nasal polyps was determined by staining with FITC-conjugated anti-CD16 (3G8, Biolegend) and analysed by flow cytometery (BD, Fortessa).

Determination of cytokine and chemokine production by ELISA Measurements of secreted cytokines were performed by sandwich ELISA in 8 or 24 -hour cell-free supernatants. The release IL-6 and 
IL-8 was detected using pairs of specific mAbs and recombinant standards obtained from BioSource International (Camarillo, USA).

Determination of FcyR expression by Western blot and flow cytometry

For Western blot, nasal epithelial cells from inferior turbinates were lysed after $24 \mathrm{~h}$ stimulation with LPS $1 \mu \mathrm{g} / \mathrm{ml}$ and $\mathrm{lgG}$ using RIPA buffer (Cell Signaling), briefly sonicated for $10 \mathrm{sec}$ at $30 \%$ and centrifuged for $10 \mathrm{~min}$ at $14,000 \times \mathrm{g}$. BCA assay was performed (Thermo Scientific) and samples were boiled with sample buffer and DTT for $15 \mathrm{~min}$ at $95^{\circ} \mathrm{C}$. Cell lysates were run on a $4-12 \%$ BisTris protein gel (Invitrogen) using MES-running buffer (Invitrogen). Proteins were transferred to a PVDF membrane (GE healthcare) using transfer buffer (Invitrogen) and blocked with 2\% milk (BioRad) afterwards. Membrane was incubated with indicated antibodies. Anti-FcyRIII antibody (CD16, Abcam); Histon H3 (Cell signaling); Polyclonal Swine anti-Rabbit immunoglobulins HRP (Dako).

To measure the FcyRIII expression, nasal polyp epithelial cells were stained with anti-FcyRlll (Abcam) followed by PE-conjugated goat anti-mouse antibody (Jackson ImmunoResearch Lab). Fluorescence was determined by flow cytometry (canto II, BD Biosciences).

Statistical analysis

Data are expressed as mean \pm SD. Assessment of statistical significance was performed using paired Student's test with GraphPad.P-values $<0.05$ were considered significant.

\section{ACKNOWLEDGEMENTS}

This work was supported by grants from the Academic Medical Center (AMC Fellowship 2015); and the Netherlands Organization for Scientific Research (NWO; VENI, project no. 91611012)

\section{AUTHOR CONTRIBUTIONS}

Conceptualization, K.G. and J.d.D; Methodology, K.G., W.H., G.D.A, J.M.B, C.M.v.D., and J.d.D,; Investigation, K.G., W.H., D.v.E., E.J.d.G., and G.D.A; Writing-Original Draft, K.G., W.H., and J.d.D. Writing-Review \& Editing, C.M.v.D., G.D.A, J.M.B., and W.J.F.; Supervision, C.M.v.D., W.J.F., and J.d.D.

\section{ADDITIONAL INFORMATION}

The online version of this article (https://doi.org/10.1038/s41385-018-0129-x) contains supplementary material, which is available to authorized users.

Competing interests: The authors declare no competing interests.

Publisher's note: Springer Nature remains neutral with regard to jurisdictional claims in published maps and institutional affiliations.

\section{REFERENCES}

1. Kawai, T. \& Akira, S. The role of pattern-recognition receptors in innate immunity: update on Toll-like receptors. Nat. Immunol. 11, 373-384 (2010).

2. Vroling, A. B., Fokkens, W. J. \& van Drunen, C. M. How epithelial cells detect danger: aiding the immune response. Allergy 63, 1110-1123 (2008).

3. van Tongeren, J. et al. Expression profiling and functional analysis of Toll-like receptors in primary healthy human nasal epithelial cells shows no correlation and a refractory LPS response. Clin. Transl. Allergy 5, 42 (2015).

4. Fokkens, W. J. et al. European position paper on rhinosinusitis and nasal polyps 2012. Rhinol. Suppl. 23, 3-298 (2012).

5. Tieu, D. D., Kern, R. C. \& Schleimer, R. P. Alterations in epithelial barrier function and host defense responses in chronic rhinosinusitis. J. Allergy Clin. Immunol. 124, 37-42 (2009).

6. Poulsen, H. L. Interstitial fluid concentrations of albumin and immunoglobulin G in normal men. Scand. J. Clin. Lab. Invest. 34, 119-122 (1974).

7. Stoop, J. W., Zegers, B. J., Sander, P. C. \& Ballieux, R. E. Serum immunoglobulin levels in healthy children and adults. Clin. Exp. Immunol. 4, 101-112 (1969).
8. Kirkeby, L., Rasmussen, T. T., Reinholdt, J. \& Kilian, M. Immunoglobulins in nasal secretions of healthy humans: structural integrity of secretory immunoglobulin A1 ( $\lg A 1)$ and occurrence of neutralizing antibodies to $\lg A 1$ proteases of nasal bacteria. Clin. Diagn. Lab. Immunol. 7, 31-39 (2000).

9. Wagner, D. K. et al. Analysis of immunoglobulin $G$ antibody responses after administration of live and inactivated influenza $A$ vaccine indicates that nasal wash immunoglobulin $G$ is a transudate from serum. J. Clin. Microbiol. 25, 559-562 (1987).

10. den Dunnen, J. et al. IgG opsonization of bacteria promotes Th17 responses via synergy between TLRs and Fc gamma Rlla in human dendritic cells. Blood 120, 112-121 (2012).

11. Moreau-Marquis S., Coutermarsh B., Stanton B. A. Combination of hypothiocyanite and lactoferrin (ALX-109) enhances the ability of tobramycin and aztreonam to eliminate Pseudomonas aeruginosa biofilms growing on cystic fibrosis airway epithelial cells. J Antimicrob Chemother. 70, 160-166 (2015).

12. Elinav, E., Strowig, T., Henao-Mejia, J. \& Flavell, R. A. Regulation of the antimicrobial response by NLR proteins. Immunity 34, 665-679 (2011).

13. Heidl, S., Ellinger, I., Niederberger, V., Waltl, E. E. \& Fuchs, R. Localization of the human neonatal Fc receptor ( $\mathrm{FCRn}$ ) in human nasal epithelium. Protoplasma 253, 1557-1564 (2016).

14. Nimmerjahn, F. \& Ravetch, J. V. Fcgamma receptors as regulators of immune responses. Nat. Rev. Immunol. 8, 34-47 (2008).

15. Newling, M. et al. Fc gamma receptor lla suppresses type I and III interferon production by human myeloid immune cells. Eur. J. Immunol. 48, 1796-1809 (2018).

16. Weinblatt, M. E. et al. An oral spleen tyrosine kinase (Syk) inhibitor for rheumatoid arthritis. N. Engl. J. Med. 363, 1303-1312 (2010).

17. Vogelpoel, L. T. et al. Fc gamma receptor-TLR cross-talk elicits pro-inflammatory cytokine production by human M2 macrophages. Nat. Commun. 5, 5444 (2014).

18. Schenten, D. \& Medzhitov, R. The control of adaptive immune responses by the innate immune system. Adv. Immunol. 109, 87-124 (2011).

19. Gillis, C., Gouel-Cheron, A., Jonsson, F. \& Bruhns, P. Contribution of human FcgammaRs to Disease with evidence from human polymorphisms and transgenic animal studies. Front. Immunol. 5, 254 (2014).

20. Vogelpoel, L. T., Baeten, D. L., de Jong, E. C. \& den Dunnen, J. Control of cytokine production by human fc gamma receptors: implications for pathogen defense and autoimmunity. Front. Immunol. 6, 79 (2015).

21. Stapleton, N. M., Einarsdottir, H. K., Stemerding, A. M. \& Vidarsson, G. The multiple facets of FcRn in immunity. Immunol. Rev. 268, 253-268 (2015).

22. Aloulou, M. et al. IgG1 and IVIg induce inhibitory ITAM signaling through FcgammaRIII controlling inflammatory responses. Blood 119, 3084-3096 (2012).

23. Macpherson, A. J., Geuking, M. B. \& McCoy, K. D. Homeland security: IgA immunity at the frontiers of the body. Trends Immunol. 33, 160-167 (2012).

24. Hansen I. S., Baeten D. L. P., den Dunnen J. The inflammatory function of human IgA. Cell. Mol. Life Sci. (2018). https://doi.org/10.1007/s00018-018-2976-8. [Epub ahead of print]

25. Hansen, I. S., Hoepel, W., Zaat, S. A. J., Baeten, D. L. P. \& den Dunnen, J. Serum IgA Immune Complexes Promote Proinflammatory Cytokine Production by Human Macrophages, Monocytes, and Kupffer Cells through FcalphaRI-TLR Cross-Talk. J. Immunol. 199, 4124-4131 (2017).

26. Schleimer, R. P. \& Berdnikovs, S. Etiology of epithelial barrier dysfunction in patients with type 2 inflammatory diseases. J. Allergy Clin. Immunol. 139, 1752-1761 (2017).

27. Hamilos, D. L. Host-microbial interactions in patients with chronic rhinosinusitis. J. Allergy Clin. Immunol. 133, 640-53 e4 (2014).

28. de Borja Callejas F. et al. Reconstituted human upper airway epithelium as 3-D in vitro model for nasal polyposis. PLoS One. 9, e100537 (2014). https://doi.org/ 10.1371/journal.pone.0100537.

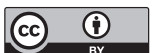

Open Access This article is licensed under a Creative Commons Attribution 4.0 International License, which permits use, sharing, adaptation, distribution and reproduction in any medium or format, as long as you give appropriate credit to the original author(s) and the source, provide a link to the Creative Commons license, and indicate if changes were made. The images or other third party material in this article are included in the article's Creative Commons license, unless indicated otherwise in a credit line to the material. If material is not included in the article's Creative Commons license and your intended use is not permitted by statutory regulation or exceeds the permitted use, you will need to obtain permission directly from the copyright holder. To view a copy of this license, visit http://creativecommons. org/licenses/by/4.0/.

(c) The Author(s) 2019 